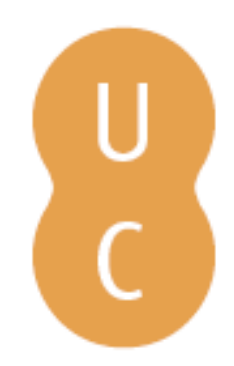

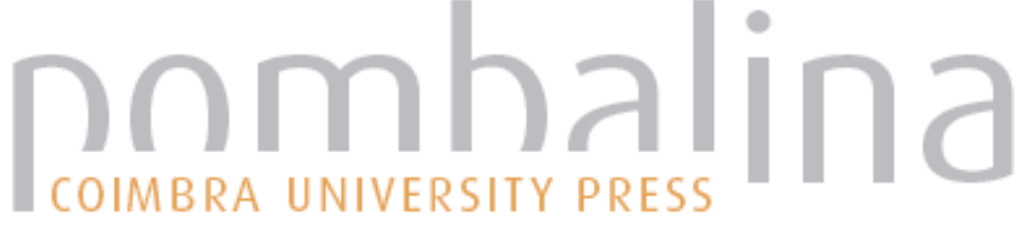

\section{Entre Cloud Gate e II Cortegiano: Portugal no espelho de Castiglione}

\author{
Autor(es): $\quad$ Marnoto, Rita
}

Publicado por: Imprensa da Universidade de Coimbra

URL

persistente: URI:http://hdl.handle.net/10316.2/38715

DOI: $\quad$ DOI:http://dx.doi.org/10.14195/978-989-26-1164-8_38

Accessed : $\quad$ 26-Apr-2023 13:55:27

A navegação consulta e descarregamento dos títulos inseridos nas Bibliotecas Digitais UC Digitalis, UC Pombalina e UC Impactum, pressupõem a aceitação plena e sem reservas dos Termos e Condições de Uso destas Bibliotecas Digitais, disponíveis em https://digitalis.uc.pt/pt-pt/termos.

Conforme exposto nos referidos Termos e Condições de Uso, o descarregamento de títulos de acesso restrito requer uma licença válida de autorização devendo o utilizador aceder ao(s) documento(s) a partir de um endereço de IP da instituição detentora da supramencionada licença.

Ao utilizador é apenas permitido o descarregamento para uso pessoal, pelo que o emprego do(s) título(s) descarregado(s) para outro fim, designadamente comercial, carece de autorização do respetivo autor ou editor da obra.

Na medida em que todas as obras da UC Digitalis se encontram protegidas pelo Código do Direito de Autor e Direitos Conexos e demais legislação aplicável, toda a cópia, parcial ou total, deste documento, nos casos em que é legalmente admitida, deverá conter ou fazer-se acompanhar por este aviso.

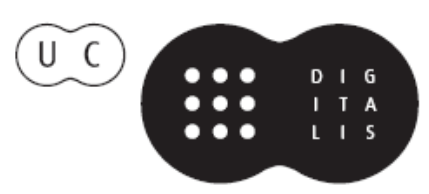


Rita Marnoto

Universidade de Coimbra

\section{ENTRE CLOUD GATE E IL CORTEGIANO. PORTUGAL NO ESPELHO DE CASTIGLIONE}

1. Cloud gate é o título da enorme escultura, que se ergue na AT\&T Plaza do Millennium Park de Chicago, concebida pelo conceituado artista plástico Anish Kapoor ${ }^{1}$. Está implantada entre uma zona edificada e uma tira de parque verde à beira do Lago Michigan. Domina toda a envolvente, e não só pela sua inserção urbana e pela sua dimensão, mas também pelo modo como as suas linhas curvas e a sua superfície espelhada jogam entre si. É como se fosse uma enorme bola esvaziada, um esferoide achatado cujos polos foram comprimidos um contra o outro. A modelação a que é sujeita essa forma esférica cria então dois espaços, o espaço exterior, que é convexo, e o espaço interior, que é côncavo. Parece suspensa no ar, e a sua superfície é inteiramente recoberta por aço espelhado. Colocada no limite entre o núcleo da cidade e o parque com o lago, faz a transição entre as duas zonas. A sua superfície exterior, convexa, reflete imagens de mundo que parecem infinitas. Por sua vez, a concavidade interior preserva, nas suas dimensões, uma escala humana, espelhando cada visitante como um filamento oblongo necessariamente agregado a todos os outros transeuntes acolhidos por Cloud gate. É assim que os efeitos de reflexão múltipla e nebulosa potenciam a desmaterialização de uma obra com mais de cem toneladas.

A associação de Il libro del cortegiano de Baldassar Castiglione a uma escultura concebida cerca de cinco séculos mais tarde tem na sua base um caráter

1 Natural de Mumbai (1954) e residente em Londres. Representou o Reino Unido na Bienal de Veneza em 1990, onde obteve o Premio Duemila. Um ano depois, recebeu o Turner Prize. 
especular de duas-obras primas, articulado entre superfície côncava e superfície convexa. Cloud gate foi montada entre 2004 e 2006. Por sua vez, o primeiro esboço do tratado de Castiglione foi elaborado na sequência da morte do duque Guidobaldo di Montefeltro, ocorrida em 1508. Depois de ter sido sujeito a uma trabalhosa composição redatorial, teve a sua primeira edição em Veneza, no mês de Abril de 1528, nas oficinas de Aldo e Andrea d'Asolo, continuadores do labor de Aldo Manuzio, à qual se seguiu nova edição, logo em Outubro do mesmo ano, em Florença, pelos herdeiros de Filippo Giunta ${ }^{2}$. Ao longo do século xvi, foram publicadas mais de cem edições do tratado, de Espanha à Polónia, o qual, por entre os caminhos dessa fulgurante difusão, passou a correr sob o mais

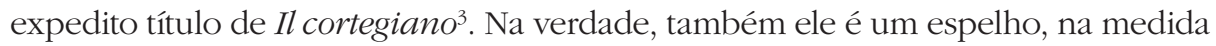
em que se insere naquela tipologia de textos, designada como speculum, que estabelece modelos de comportamento a serem seguidos e imitados ${ }^{4}$.

A escultura de Kapoor existe em função da superfície espelhada que a recobre interior e exteriormente. O tratado de Castiglione tem por cerne a sua capacidade de, partindo da corte de Urbino, refletir e projetar "una regula universalissima, la qual mi par valer circa questo in tutte le cose umane che si facciano o dicano più che alcuna altra”, como o afirma, logo nas primeiras páginas

2 São duas das mais destacadas tipografias da época, cujo programa editorial segue vias paralelas, o que gerou, não raro, relações de concorrência. Mostra-o desde logo o uso diferenciado previsto por cada uma das edições de Il cortegiano. A de abril, com as suas grandes páginas in folio, visa um manuseamento em local preparado para a leitura, ao passo que a de outubro, em oitavo, é um volume maneirinho. Sobre a história do texto, são essenciais os estudos pioneiros de Vittorio Cian, com relevo para "Un episodio della censura in Italia nel secolo xvi: l'edizione spurgata del Cortegiano", Archivio Storico Lombardo, 1887, pp. 661-727; Nel mondo di Baldassarre Castiglione, Venezia, Ferrari, 1892; "Nel mondo di Baldassarre Castiglione. Documenti illustrati", Archivio Storico Lombardo, 1942, pp. 3-97; La lingua di Baldassarre Castiglione, Firenze, Sansoni, 1942; e a sua edição de Il libro del cortegiano, Firenze, Sansoni, 1947; bem como os trabalhos de Guido Ghinassi, "L’ultimo revisore del Cortegiano", Studi di Filologia Italiana, 21, 1963, pp. 217-264; "Fasi dell'elaborazione del Cortegiano", Studi di Filologia Italiana, 25, 1967, pp. 155-196; "Postille sull'elaborazione del Cortegiano", Studi e Problemi di Critica Testuale, 3, 1971, pp. 171-178; e a sua edição de La seconda redazione del "Cortegiano", Firenze, Sansoni, 1968.

3 Cerca de metade dessas edições saíram em italiano, e das restantes onze são em latim. Ver Peter Burke, The Fortunes of the "Courtier", Cambridge, Polity Press, 1995.

4 Sobre os tratados de specula, escritos em latim ou em italiano, que em Itália precederam e deram sequência a Il cortegiano, formando um modelo de difusão europeia, ver Amedeo Quondam, La conversazione. Un modello italiano, Roma, Donzelli, 2007. Em Portugal, a tipologia do espelho de Príncipes foi estudada por Nair de Nazaré Castro Soares, O Príncipe ideal no século xVI e a obra de D. Jerónimo Osório, Coimbra, INIC, 1994. Ver também, na sua incidência ibérica, Davide Bigalli, Immagini del Principe. Ricerche su politica e Umanesimo nel Portogallo e nella Spagna del Cinquecento, Milano, F. Angeli, 1985. 
de Il libro del cortegiano, o conde Ludovico da Canossa ${ }^{5}$. Essa regra espelha a prática quotidiana do cortesão e da mulher de corte, num quadro dotado de larguíssimo espectro.

Dos reflexos de Portugal em Il cortegiano, tratarei dois aspetos proeminentes ${ }^{6}$. O primeiro, é a sua dedicatória a D. Miguel da Silva, bispo de Viseu. O segundo, a famosa facécia do jogo de xadrez, contada no LVI capítulo do segundo livro, que se passa na corte portuguesa'.

Este ensaio homenageia uma Professora, a Doutora Ofélia Paiva Monteiro, que, de forma não muito habitual, sempre estimulou os seus discípulos a estudarem o passado dando atenção ao presente, e a interpretarem a obra literária no seio de um conjunto de manifestações artísticas de fronteiras amplas, fazendo dessa atitude uma via privilegiada de indagação heurística.

2. Quatro anos antes de Il cortegiano ter sido dado à estampa, já Vittoria Colonna manifestava a sua admiração pelo lustro de uma obra que lhe parecia escrita à frente de um espelho. No plano da língua, a Marquesa de Pescara não poupa louvores à modelação da matéria utilizada, o vulgar, levada a cabo com tanta mestria que, no seu dizer, faz o bronze luzir como ouro. Mas é na apresentação de facetas interiores e exteriores, entre a projeção num espelho da figura do próprio autor e de uma tipologia social em vias de formação, que identifica o sucesso do retrato do perfetto cortegiano ${ }^{8}$,

Ma non tacerò già quello che più admirazione mi ha causato, che è che a me pare che chi scrive latino habbi una differenzia con li altri autori, simile ad uno artefice

5 Baldassar Castiglione, Il libro del cortegiano, ed. Amedeo Quondam, note Nicola Longo, Milano, Garzanti, 1990 [1981], p. 59.

6 O assunto tem por contraponto a receção de $I l$ cortegiano na literatura portuguesa, à qual tive ocasião de me referir em "Crítica à corte e antinomia urbana", Filologia e Literatura, coordenação Maurizio Perugi, Lisboa, Genève, Colibri, 2012 [no prelo].

7 Quanto ao conceito de imagem e à tão debatida questão da imagologia, toma-se por referência a perspetiva crítica de Hugo Dyserinck, quando coloca no cerne da análise o plano literário, pelo contributo que o seu estudo efetivamente pode fornecer para um melhor conhecimento de aspectos essenciais do texto. Valha por todas a remissão para o seu artigo, "Zum Problem der images und mirages und ihrer Untersuchung im Rahmen der Vergleichenden Literaturwissenschaft", Arcadia, 1, 2, 1966, pp. 107-120.

8 A carta é datada de Marino, 20-9-1524. Foi integralmente transcrita no primeiro anexo de Amedeo Quondam, "Questo povero Cortegiano". Castiglione, il Libro, la Storia, Roma, Bulzoni, 2000, pp. 534-535. 
che lavora di oro a quelli che lavorano di rame, ché per semplice opera che faccia, la excellenzia de la materia luce tanto che la dimostra bella; ma la opera di rame con grande ingegno et sottil modo non può farsi tale che in la comparazione non perda molto; ed il novo vostro vulgare porta una maestà con seco sì rara, che non deve cedere a niuna opera latina.

Che abbia ben formato un perfetto cortegiano non me ne maraviglio, ché con solo tenere uno specchio denanzi et considerare le interne et externe parti sue, posseva descriverlo qual lo ha descritto; ma essendo la maggior difficultà che habbiamo conoscer noi stessi, dico chè più difficile li è stato formar sé che un altro, sì che o per l'uno o per l'altro che sia, merita tanta laude che me ne rimetto al signor Datario, il qual solo giudico bastevole che per me la dia.

É nestes termos que a Marquesa de Pescara termina a carta enviada a Castiglione em 20 de setembro de 1524. Para além do interesse que apresenta, pela exploração da imagem do espelho, trata-se de um texto importante para a compreensão de dois tópicos essenciais ao desenvolvimento do presente estudo, que enunciarei sinteticamente.

O primeiro relaciona-se com um processo de elaboração textual extremamente laborioso. Ao longo de quase duas décadas, é com grande entusiasmo que Castiglione dedica os seus mais pressurosos cuidados à redação do tratado. Contudo, a partir de um certo momento essa gestação converter-se-á em fonte de grandes preocupações. Se a obra é escrita em diálogo, Castiglione vai acompanhando a sua feitura com a auscultação de opiniões e impressões acerca do seu teor. Envia, pois, o seu Cortegiano a algumas das mais destacadas personalidades da cena literária italiana do seu tempo, dinamizando uma rede de relações detalhadamente descrita por Amedeo Quondam?. Põe tanto empenho nesse intercâmbio de ideias, que é ele próprio a acompanhar a feitura dos manuscritos que vai distribuindo. Em setembro de 1518, de Mântua, onde se encontra, faz chegar o tratado a Roma, aos dois secretários do papa Leão X, Iacopo Sadoletto e Pietro Bembo. Também para Ferrara segue uma cópia, destinada ao cardeal Ippolito d'Este, segundo uma carta datada de junho de 1520, escrita de Mântua. Depois da morte do Cardeal, ocorrida em novembro desse mesmo ano, passará

9 Ib., "Parte prima". 
para as mãos de Alfonso Ariosto. Um outro manuscrito é posteriormente enviado a Vittoria Colonna. Entretanto, o apreço que uma obra tão inovadora vai merecendo leva a que os pedidos de leitura se multipliquem, e até Mario Equicola é envolvido nessa malha de relações.

As anotações apostas a alguns desses manuscritos são fontes preciosas para o conhecimento de uma dinâmica textual que volteia em torno dos comentários e das sugestões de Sadoletto, Bembo ou Alfonso Ariosto. A isso há a acrescentar, contudo, a angústia com que Castiglione se esforça por recuperar uma das cópias. O eventual uso que dela possa ser feito não lhe dá muito sossego. É o caso do manuscrito em posse de Vittoria Colonna, cuja devolução vai sendo protelada. $\mathrm{Na}$ verdade, o excerto transcrito faz parte de uma carta em que a Marquesa se justifica pela sua demora, dizendo que o deseja ler uma segunda vez, com mais vagar. Que a primeira leitura fora profunda, não há lugar para dúvidas. A análise que faz do tratado é aprimorada. Mas a agitação que essa demorada leitura causou no espírito de Castiglione não foi de pouca monta.

A partir de 1513, ano em que é nomeado Embaixador do Duque de Urbino em Roma, Castiglione passa longos períodos na cidade papal. À medida que os anos vão passando, essa ligação ao ambiente romano torna-se cada vez mais intrínseca. Entretanto, Clemente VII designa-o Núncio Pontifício em Espanha, para onde parte em inícios de 1525. A missão era delicada, num momento em que já se respirava aquele novo equilíbrio de forças que levaria ao saque de Roma. Contudo, para além desses cuidados, o Núncio de Clemente VII carregava consigo outras preocupações: o destino do manuscrito que não conseguia reaver. Deviam ser profundas se, apesar de se encontrar fora de Itália, toma a resolução de editar Il libro del cortegiano. Apoia-se, para isso, numa rede de amigos e intermediários que o ajudam na empresa, com relevo para Ludovico da Canossa e Giovanni Battista Ramusio ${ }^{10}$.

Ainda assim, o mestre da sprezzatura não se consegue conter, se logo no início do prefácio com que se abre a edição de Il cortegiano desabafa ${ }^{11}$,

10 Secretário da República e colaborador próximo dos Manuzio, Ramusio (Treviso, 1485-Pádua, 1557) interessou-se muito, como é sabido, por cartografia e pelas navegações portuguesas. Compilou dezenas de relatos hodepóricos nos três volumes de Delle navigationi et viaggi (vol. 1, 1550; vol. 3, 1556; vol. 2, 1559, póstumo).

11 Il libro del cortegiano, pp. 3-4. 
Ritrovandomi adunque in Ispagna ed essendo di Italia avvisato che la signora Vittoria dalla Colonna, marchesa di Pescara, alla quale io già feci copia del libro, contra la promessa sua ne avea fatto trascrivere una gran parte, non potei non sentirne qualche fastidio, dubitandomi di molti inconvenienti, che in simili casi possono occorrere; nientedimeno mi confidai che l'ingegno et prudenzia di quella Signora, la virtù della quale io sempre ho tenuto in venerazione come cosa divina, bastasse a rimediare che pregiudicio alcuno non mi venisse dall'aver obedito a' suoi comandamenti. In ultimo seppi che quella parte del libro si ritrovava in Napoli in mano di molti; e, come sono gli omini sempre cupidi di novità, parea che quelli tali tentassero di farla imprimere. Ond'io, spaventato da questo periculo, diterminaimi di riveder sùbito nel libro quel poco che mi comportava il tempo, con intenzione di pubblicarlo; estimando men male lasciarlo veder poco castigato per mia mano che molto lacerato per man d'altri.

O tratado sobre a impassibilidade abre-se, pois, com uma manifestação do fastidio e do spavento que correm por conta de uma Senhora, cujo ingegno, cuja prudenzia e cuja virtù merecem divino louvor.

Quanto ao segundo tópico a considerar, diz respeito à incidência do modelo proposto, entre formar sé e formar un altro, como escreve Vittoria Colonna. O perfetto cortigiano consubstancia uma imagem onde convergem os dotes do autor do livro e da sociedade de corte italiana, para ganhar uma dimensão europeia. Bem nota Amedeo Quondam que as suas personagens fazem ou poderiam fazer parte de uma galeria de pintura da época. Aliás, Castiglione manteve relações de amizade intelectual com Raffaello. Os primeiros retratos de figuras de corte que pintou acompanharam a germinação do tratado, e não só em termos cronológicos, como também no que toca à convivência de ambos na corte de Urbino ${ }^{12}$.

12 A esse propósito, Amedeo Quondam, salvaguardando algumas atribuições problemáticas, recorda os retratos de várias personagens de Il cortigiano, a saber, "L'Elisabetta Gonzaga ora agli Uffizi (a tergo si legge questa scritta: "Isabetta mantovana moglie del duca Guido"), l'Emilia Pio ora nella Collezione Epstein di Baltimora, il Francesco Maria della Rovere degli Uffizi, i due San Giorgio e il drago per Enrico VII d'Inghilterra (ora al Louvre e alla National Gallery di Washington), il Guidubaldo degli Uffizi; per non dimenticare il perduto ritratto di Pietro Bembo (del 1506), nonché, sempre per diretta pertinenza com il Cortegiano, quello di Federico Gonzaga, anch'esso perduto, o quello di cardinale ora al Prado (ove è riconoscibile, secondo alcuni, il Bibbiena, e secondo altri Ippolito d'Este)", ao que acrescenta a presença da figura de Castiglione nos frescos que Raffaello pintou para a Stanza della Segnatura, a Scuola d'Atene e o Parnaso, e para a Sala di Costantino ("Questo povero Cortegiano". Castiglione, il Libro, la Storia, pp. 510-511). 
Na verdade, cada uma dessas telas poderia representar muitas outras personalidades do tempo, e não são poucos os problemas tantas vezes suscitados pela identificação das personagens retratadas. Da mesma feita, a Urbino que Castiglione escolhe como cenário do seu diálogo é uma de entre as tantas refinadas cortes italianas da época, que por sinal está longe de ser uma das maiores. A escolha em muito se deve às suas ligações com Guidobaldo di Montefeltro, deixando porém largo espaço para uma leitura aberta. O modelo de corte e de cortesão que apresenta, por um lado, é bem enraizado na história, mas, por outro lado, é suscetível de ser posto em prática em qualquer corte italiana ou europeia, seja a sua dimensão mais restrita ou mais ampla. Com efeito, o tratado mantém claríssimos elos de ligação com o ambiente cortesanesco de Urbino, a começar pelos nomes dos intervenientes, embora o processo redatorial mostre que muitas dessas particularidades vão sendo atenuadas, e também as vivências pessoais do próprio Castiglione ganham discrição. Dessa forma, é conferida maleabilidade a um modelo que, para além de italiano, é europeu. Tanto se aplica a Urbino como a Roma, e tanto se adaptará a Madrid como a Versalhes. Urbino vale por um esplendor que é chamado à colação com uma elegância que dele faz espelho natural.

Paralelamente, toma forma, nesse processo de reelaboração, o reconhecimento dos usos de várias populações europeias, a ponto de o que era considerado próprio dos bárbaros passar a ser tido como uma marca de alteridade. "Castiglione sostituisce, infatti, il polemico, troppo polemico, "gli Italiani son vaghi d'abbigliarsi alla foggia de' barbari» con il neutro "alle altrui foggie»", observa Quondam a propósito das alterações que vão sendo introduzidas no texto ${ }^{13}$. O estrangeiro deixa de ser o bárbaro, para se inserir numa prática relacional entre nações, cada uma das quais preserva a sua identidade, num equilíbrio difícil, é certo, mas efetivo, entre local e geral. A tal regula universalissima corresponde ao novo modelo italiano, por ser o mais perfeito e o mais internacional, no sentido em que é adequado a todas as circunstâncias da história. Mas esse modelo de forma alguma anula caraterísticas de temperamento e hábitos próprios de Francesi, Spagnoli, Tedeschi, Portoghesi, Turchi, Moscoviti e tantos outros.

13 Ib., p. 385. Sobre a alteridade e a questão do estrangeiro, são essenciais as pp. 309-470 deste volume. 
3. A dedicatória de Il cortegiano a D. Miguel da Silva, bispo de Viseu, insere-se numa complexa trama onde se adensam questões do plano histórico e pessoal, bem como de ordem textual e editorial.

D. Miguel da Silva era uma das mais distintas personalidades da Roma do tempo de Castiglione. Tiveram relações de grande proximidade, frequentaram os mesmos círculos intelectuais e até moraram juntos, entre 1520 e 1522, no Palácio de Belvedere, situado a norte da Basílica de S. Pedro. Sylvie Deswarte, na monografia que dedicou a D. Miguel da Silva, transcreve o poema latino de Guido Postumo Silvestre que coloca o destinatário e o autor de Il cortegiano lado a lado, por ocasião de uma caçada nos arredores de Roma organizada pelo papa Leão $\mathrm{X}^{14}$,

Quin lusitano orator quocque missus ab orbe

Sylvius Hispani terga onerarat equi.

Ibat suspenso similis quem magna putatis

Concipere, ac Regi mox referenda sua.

Aut si quod musis gratum acceptumque canebat

Cortigere aeternae posteritatis opus.

Is comitem Gibertum altis de rebus agentem

Iunxerat, et Phoebi Castiliona decus,

Armatam ferro cornum de more gerebat

Missile telum illi fulminis instar erat.

— O que poderá ser assim traduzido para português:

Que também o embaixador enviado das terras lusitanas,

Silva, montava na garupa de um cavalo espanhol.

Ia como quem está absorto na conceção de grandes ações,

a relatar em breve ao seu Rei.

Ou então ia a compor algo de caro e de agradável às Musas,

14 Il "perfetto cortegiano" D. Miguel da Silva, Roma, Bulzoni, 1989, pp. 27-29 e 185, que apresenta e transcreve o poema, e donde se cita. Foi originariamente editado no volume, Guidi Posthumi Silvestri Pisaurensis, Elegiarum libri II, Impressum Bononiae, per Hieronymum de Benedictis Bibliopolam Bononiensem, 1524 calen Iul., c xcII v. Ver também Amedeo Quondam, "Questo povero Cortegiano". Castiglione, il Libro, la Storia, p. 502, n. 
obra digna de eterna posteridade na corte.

Tinha como companheiro Giberto que de altos assuntos se ocupava

e Castiglione, honra de Febo.

Como de costume levava o arco armado de ferro

e a flecha que lançava era semelhante ao relâmpago.

Nomeado Embaixador por D. Manuel, chega a Roma em finais de 1514 ou em inícios do ano seguinte, para regressar a Portugal por meados de 1525. Já anteriormente viajara por Itália, e lá se irá refugiar em 1540, quando o jogo político de D. João III lhe é adverso, acabando por falecer em Roma no ano de 1556. Em 1525, é elevado a Bispo de Viseu, e em 1541, a Cardeal. O esplendor dos papas Leão X, Adriano VI e Clemente VII coincidia com a grande época das navegações portuguesas. Roma, que recebeu faustosas embaixadas de Portugal, encontrava-se deslumbrada por tais façanhas, e com a Cidade Eterna toda a Europa.

As ligações de D. Miguel da Silva aos Medici proporcionaram-lhe uma rápida integração. Conviveu assiduamente com Giovanni Ruscellai e Giangiorgio Trissino, acompanhou as incursões no campo da alquimia de Tommaso Masini, a quem chamavam "o Zoroastro". Frequentou reuniões dos homens de letras ligados à cúria romana, os orti letterari muito em voga na época, e participou na Accademia tragica a que Rucellai presidia, no Castel Sant'Angelo. Esses eram os círculos de Angelo Colocci, Pietro Bembo, Iacopo Sadoletto, Egidio da Viterbo, Claudio Tolomei, Giani Lascaris, Ludovico Ariosto, Hans Goritz, Lattanzio Tolomei e de tantas outras figuras de proeminente relevo, de entre as quais o próprio Baldassar Castiglione. De resto, os interesses de D. Miguel eram muito vastos, estendendo-se, da literatura, às gravações epigráficas egípcias, à astronomia ou à filologia. No campo das artes e da arquitetura, acompanhou os trabalhos de Giuliano da Sangallo, Antonio da Sangallo e Raffaello em S. Pedro. A famosa carta-programa sobre a arquitetura renascentista que Castiglione e Raffaello elaboraram conjuntamente e dirigiram a Leão X foi maturada por esses anos, quando artistas e intelectuais que com eles conviviam, e de entre os quais se contava D. Miguel da Silva, visitavam conjuntamente monumentos de Roma ${ }^{15}$.

15 Para uma visão global das relações entre Portugal e Itália durante esse período, com direta incidência no domínio das artes plásticas, ver Sylvie Deswarte, Ideias e imagens de Portugal na época dos descobrimentos. Francisco de Holanda e a teoria da arte, trad. de Maria Alice Chicó, Lisboa, Difel, 1992. 
Note-se que algumas das figuras citadas foram destinatários diretos dos manuscritos de Il cortegiano que Castiglione preparou para serem discutidos e comentados, sendo de admitir que a sua leitura fosse levada a cabo nesses selectos círculos intelectuais. Além disso, a inflexão no sentido de um neoplatonismo mais espiritualizado, conforme ilustrada pela redação de 1518, acompanha, afinal, as dominantes ideológicas do ambiente em que D. Miguel da Silva se integrava ${ }^{16}$.

Durante a permanência em Espanha de Castiglione, as conversações da casa reinante com Portugal e a troca de embaixadas foram frequentes, tendo em vista, particularmente, a preparação do casamento de Carlos V com D. Isabel, irmã de D. João III. Castiglione e D. Miguel da Silva não se teriam encontrado de novo, mas os seus rumos coincidiram, na estadia de um em Espanha e no regresso do outro a Portugal.

Segundo Deswarte, a dedicatória de Il cortegiano a D. Miguel da Silva é sinal do realismo político que levou o seu autor a situar-se, cautelosamente, em terreno neutro, sem pender para a fação papal ou para a fação imperial ${ }^{17}$. Aliás, a dedicatória a D. Miguel da Silva de uma obra-chave para a literatura italiana e para a literatura europeia do século xvi não é sem precedentes. A edição de $I l$ Petrarca batida em Florença, no ano de 1522, pelos herdeiros de Filippo Giunta, fora igualmente dedicada ao Embaixador português em Roma ${ }^{18}$. Contudo, a dedicatória de Il cortegiano tem uma particularidade, a de ser dupla, pois cada um dos quatro livros em que a obra se divide é dedicado a Alfonso Ariosto.

Alfonso Ariosto (1475-1525), primo do poeta Ludovico Ariosto, era amigo íntimo de Castiglione. Sabe-se que esteve ao serviço da família d'Este em Ferrara, mas admite-se que Castiglione e Alfonso Ariosto se pudessem ter conhecido precedentemente, na corte de Milão. Se se percorrerem os vários manuscritos do tratado que Castiglione preparou e pôs a circular antes de o editar, verifica-se que, apesar das complexas metamorfoses redatoriais em curso, a dedicatória a

\footnotetext{
16 Ver Sylvie Deswarte, "O poeta e o pintor coroados de louros", in Petrarca 700 anos, coordenação de Rita Marnoto, Coimbra, Instituto de Estudos Italianos da FLUC, 2005, pp. 341-381.

17 Il "perfetto cortegiano" D. Miguel da Silva, pp. 74-78.

18 Trata-se, por sinal, da mesma tipografia que imprimiu a segunda edição de Il cortegiano, em outubro de 1528, quatro meses depois de ter saído a primeira, em Veneza, na tipografia de Aldo e d'Andrea d'Asolo.
} 
Alfonso Ariosto se mantém ${ }^{19}$. Com certeza que devem ser salvaguardadas algumas especificidades. No esboço autógrafo mais antigo que se conhece (A, que continua a pertencer à família de Castiglione, de Mântua, Ms. II 3 b), o texto não se encontra dividido em livros, pelo que há uma única dedicatória inicial. O códice B (Vat. Lat. 8204) é mutilado, faltando o princípio. A versão manuscrita final de Il libro del cortegiano encontra-se hoje depositada na Biblioteca Laurenziana de Florença (Ms. Ashburnham 409). Castiglione enviou-a para Veneza em abril de 1527, com vista à edição. O primeiro livro tem por incipit, a garrafais, "A Messer Alfonso Ariosto", uma epígrafe que se repete, ipsis verbis, no início do segundo, do terceiro e do quarto livros. No final, é registado o explicit, "Finisse il libro del conte Baldesar Castiglione intitulato a m. Alphonso Ariosto”. Está, porém, riscado e não passou à edição, pelo que a rasura será possivelmente uma indicação tipográfica. Como tal, no manuscrito que contém a versão final da obra, o nome de D. Miguel da Silva não figura.

Neste nó de questões, um dado que tem o maior relevo são as circunstâncias em que Castiglione dava aos prelos o tratado. Uma obra cuja elaboração fora maturada lentamente, ao longo de quase duas décadas, era intempestivamente editada, e sob grande pressão, a avaliar pela forma como expõe sem rodeios a preocupação de que fosse impressa uma edição-pirata do seu Cortegiano, estando ele fora de Itália, como acima se explicou. No Ashburnham 409, os sucessivos incipit dos quatro livros e o explicit do tratado mantêm entre si perfeitas relações de coerência interna. Falta-lhes, porém, coerência externa, a patir do momento em que Alfonso Ariosto falecera inesperadamente em junho de 1525 e não é habitual dedicar-se um livro a um morto.

Contudo, a princeps editada em Veneza, no mês de abril de 1528, nas oficinas de Aldo e Andrea d'Asolo, abre-se com um texto que não figura no Ashburnham 409, intitulado, em garrafais, "Al reverendo ed illustre Signor Don Michel de Silva vescovo di Viseo”. Foi acrescentado numa fase ulterior do trabalho tipográfico, como o mostra a paginação do volume. É composto por cadernos regulares, à exceção do último que é feito com três folhas, e do primeiro que apenas leva duas folhas. Castiglione enviou esse texto-dedicatória para Veneza quando o

19 Sobre o assunto, é essencial Amedeo Quondam, "Questo povero Cortegiano". Castiglione, il Libro, la Storia, pp. 471-525. 
trabalho se encontrava quase pronto, pelo que a única possibilidade foi antepor um pequeno maço ao volume já preparado. Tratou-se, pois, de uma decisão de última hora. Contudo, o nome de Alfonso Ariosto não foi retirado do início dos quatro livros, mas tão só do explicit. É logo o primeiro dos quatro livros a abrir-se em ameno colóquio com esse destinatário ${ }^{20}$,

Fra me stesso lungamente ho dubitato, messer Alfonso carissimo, qual di due cose più difficil mi fusse; o il negarvi quel che con tanta instanzia più volte m’avete richiesto, o il farlo: perché da un canto mi parea durissimo negar alcuna cosa, e massimamente laudevole, a persona ch'io amo sommamente e da cui sommamente mi sento esser amato; dall'altro ancor pigliar impresa, la quale io non conoscessi non poter condur a fine, pareami disconvenirsi a chi estimasse le giuste riprensioni quanto estimar si debbano. In ultimo, dopo molti pensieri, ho deliberato esperimentare in questo quanto aiuto porger possa alla diligenzia mia quella affezione e desiderio intenso di compiacere, che nell'altre cose tanto sòle accrescere la industria degli omini.

Voi adunque mi richiedete ch'io scriva qual sia, al parer mio, la forma di cortegiania più conveniente a gentilomo che viva in corte de' principi, per la quale egli possa e sappia perfettamente loro servire in ogni cosa ragionevole, acquistandone da essi grazia e dagli altri laude; in somma, di che sorte debba esser colui, che meriti chiamarsi perfetto cortegiano, tanto che cosa alcuna non gli manchi. Onde io, considerando tal richiesta, dico che, se a me stesso non paresse maggior biasimo l'esser da voi reputato poco amorevole che da tutti gli altri poco prudente, arei fuggito questa fatica, per dubbio di non esser tenuto temerario da tutti quelli che conoscono come difficil cosa sia, tra tante varietà di costumi che s'usano nelle corti di Cristianità, eleggere la più perfetta forma e quasi il fior di questa cortegiania, perché la consuetudine fa a noi spesso le medesime cose piacere e dispiacere; [...]

20 Il libro del cortegiano, pp. 15-16. 
Foi assim que Il cortegiano passou a ter dois destinatários, D. Miguel da Silva e Alfonso Ariosto ${ }^{21}$.

Por entre todas as atribulações editoriais, a nova introdução enviada de Espanha oferece oportunidade, a Castiglione, de fazer um ponto de situação acerca de um tratado prestes a correr mundo. A estrutura do seu texto é muito clara. A primeira parte é escrita sob o signo da morte; a segunda é dedicada à questão da língua; e, na terceira, fica contida uma dissertação sobre os objetivos do livro e o retrato do perfetto cortegiano. A dedicatória a D. Miguel da Silva abre-se com a evocação Guidobaldo di Montefeltro, desaparecido em 1508, do qual Castiglione diz ter recebido os primeiros estímulos à elaboração do tratado. Segue-se imediatamente a já citada explicação acerca da intempestiva decisão de dar o livro aos prelos, que tem a ver com o referido episódio de Vittoria Colonna. Fica encaixada entre a referência necrológica inicial a Guidobaldo, mais destacada, e a enumeração e evocação de outras personalidades ligadas à história do livro, também elas já falecidas. Começa com Alfonso Ariosto e o seu encómio. Por paradoxal que pareça, no corpo do prólogo "Al reverendo ed illustre Signor Don Michel de Silva vescovo di Viseo", Castiglione continua a suster que a obra é dedicada a esse seu amigo ${ }^{22}$,

[...] Morto è il medesimo messer Alfonso Ariosto, a cui il libro è indirizzato, giovane affabile, discreto, pieno di suavissimi costumi ed atto ad ogni cosa conveniente ad omo di corte.

21 A isto se acrescenta a exortação à cruzada, que numa primeira fase redatorial se alongava pela exortação do Re Cristianissimo (fórmula através da qual era tradicionalmente designado o Rei de França, ao caso Francisco I) a que organizasse uma campanha militar contra o maometano. Apesar de ter sido associada a um terceiro plano da dedicatória, trata-se tão só de uma invocação laudatória ao gosto da época. Pode ser confrontada com o apelo aos Reis cristãos contido no XVII canto do Orlando Furioso, cujo teor ressoa nas estrofes iniciais do VII canto de Os Lusíadas. Mesmo assim, Castiglione fez cortes drásticos nesse passo, numa atitude que terá na sua base quer motivos históricos, quer motivos literários. Ao imperador Maximiliano, sucede, em 1519, Carlos V, gorando as esperanças alimentadas por Francisco I de França de vir ainda a cingir a coroa imperial. Por sua vez, Fernando o Católico, de Aragão, que enfrentara o turco, falecera em 1516. O próprio Castiglione era Núncio Apostólico na pátria de Carlos V desde inícios de 1925. Como tal, o ideal de cruzada perdera impacto, e só mais de uma década volvida viria a ganhar nova consistência, com as incursões de Carlos V contra o turco. De resto, pela sua extensão, o passo suprimido criaria um desequilíbrio na economia do texto.

22 Il libro del cortegiano, pp. 4-5. 
Acrescenta-se a recordação dos falecidos Giuliano dei Medici (1479-1516), do cardeal Bernardo Divizi da Bibbiena (1470-1520), de Ottaviano Fregoso (1470-1524) e da própria duquesa Elisabetta Gonzaga (1471-1526). É nessa sequência que Castiglione, através de um hábil lance de retórica, enquadra o novo destinatário de Il libro del cortegiano, apostrofando- $\mathrm{O}^{23}$,

E perché voi né della signora Duchessa né degli altri che son morti, fuor che del duca Iuliano e del Cardinale di Santa Maria in Portico, aveste noticia in vita loro, acciò che, per quanto io posso, l'abbiate dopo la morte, mandovi questo libro come un ritratto di pittura della corte d'Urbino, non di mano di Raffaello o Michel Angelo, ma di pittor ignobile e che solamente sappia tirare le linee principali, senza adornar la verità de vaghi colori o far parer per arte di prospettiva ciò che non è.

"Miguel da Silva è, in realtà, una funzione del destinatario che il Libro del Cortegiano ha progettato per sé”, comenta Amedeo Quondam²4. Com efeito, o passo transcrito consubstancia a única referência que lhe é feita e o encómio não é direto. Il cortigiano é-lhe dedicado, para que possa conhecer uma roda de personalidades distintas, o que pressupõe, com efeito, uma relação de homogeneidade, mas já desaparecidas. A partir desse ponto de articulação, as atenções logo se deslocam, do destinatário, para a obra propriamente dita, "un ritratto di pittura".

4. Quanto ao segundo aspeto a tratar, a facécia que se passa na corte portuguesa enquadra-se naquela arte de contar episódios interessantes e adequados a um convívio prazenteiro. O cortesão deve saber contar a história apropriada ao ambiente em que se encontra, com aquela desenvoltura e aqueles dotes discursivos que induzem à festa e ao riso de modo discreto. Mas essas ocasiões convertem-se também em oportunidade para mostrar a agudeza, o engenho e a presença de espírito de quem conta ou comenta o entrecho. Enfim, traz para a ribalta a arte da conversação como grande fundamento da sociabilidade.

\footnotetext{
23 Ib., p. 6.

24 “Questo povero Cortegiano". Castiglione, il Libro, la Storia, p. 504.
} 
A facécia do capítulo 56 do segundo livro, contada por Bernardo da Bibbiena, é desde logo apresentada como non tanto sottile, pur bella ${ }^{25}$,

"Parlandosi pochi dì sono del paese o mondo novamente trovato dai marinari portoghesi, e dei varii animali e d'altre cose che essi di colà in Portogallo riportano, quello amico del qual v'ho detto affermò aver veduto una simia di forma diversissima da quelle che noi siamo usati di vedere, la quale giocava a scacchi eccellentissimamente; e, tra l'altre volte, un dì essendo innanzi al re di Portogallo il gentilom che portata l'avea e giocando con lei a scacchi, la simia fece alcuni tratti sottilissimi, di sorte che lo strinse molto; in ultimo gli diede scaccomatto; per che il gentilomo turbato, come soglion esser tutti quelli che perdono a quel gioco, prese in mano il re, che era assai grande, come usano i Portoghesi, e diede in su la testa alla simia una gran scaccata; la qual sùbito saltò la banda, lamentandosi forte, e parea che domandasse ragione al Re del torto che le era fatto. Il gentilomo poi la reinvitò a giocare; essa avendo alquanto ricusato con cenni, pur si pose a giocar di novo e, come l'altra volta avea fatto, così questa ancora lo ridusse a mal termine; in ultimo, vedendo la simia poter dar scaccomatto al gentilom, con una nova malizia volse assicurarsi di non esser più battuta; e chettamente, senza mostrar che fosse suo fatto, pose la man destra sotto 'l cubito sinistro del gentilomo, il quale esso per delicatura riposava sopra un guancialetto di taffetà, e prestamente levatoglielo, in un medesimo tempo con la man sinistra gliel diede matto di pedina e con la destra si pose il guancialetto in capo, per farsi scudo alle percosse; poi fece un salto inanti al Re allegramente, quasi per testimonio della vittoria sua. Or vedete se questa simia era savia, avveduta e prudente." Allora messer Cesare Gonzaga, "Questa è forza," disse, "che tra l'altre simie fosse dottore, e di molta autorità; e penso che la Republica delle simie indiane la mandasse in Portogallo per acquistar riputazione in paese incognito." Allora ognun rise e della bugia e della aggiunta fattagli per messer Cesare.

Logo de início, fica patente a imagem-padrão que a Itália e a Europa se fazem do cortesão português, homem de mar e introdutor de novos animais e de outras exóticas realidades no velho continente. Aliás, a formulação "paese o

25 Il libro del cortegiano, pp. 201-203. 
mondo novamente trovato" remete para um código de comunicação dotado de extrema atualidade epocal, o novo mondo de Vespucci ${ }^{26}$. Quanto aos animais nunca vistos que os portugueses trazem para a Europa, o facto era patente na cúria, com o elefante indiano e o rinoceronte, que acabou por ser embalsamado, enviados por D. Manuel a Leão $\mathrm{X}^{27}$. No que toca ao xadrez, trata-se um jogo muito comum nas cortes da época. Contudo, a ideia de que se tivesse difundido, pela Europa, na sequência dos contactos entre árabes e portugueses, sublinhava o seu enraizamento nos hábitos da corte lusa. De resto, uma das autoridades do enxadrismo quinhentista era um português que se apresentava como Damiano de Odemira, autor do tratado Questo libro è da imparare giocare a scachi et de le partite, editado em Roma por Stephanum Guilliretti et Herculem Nani em $1512^{28}$.

Vários são os elementos da história que divertem pelo exagero, como é típico deste género de narrativa breve: um macaco como nunca se vira, tão especial que sabe jogar xadrez, tão dotado que é capaz de impor cheque-mate, reiteradamente, ao cortesão que o trouxe para a Europa e o levou até aos reais aposentos, tão esperto que põe uma almofada na cabeça para minorar os danos da agressão que pressente. Para além disso, fica uma outra zona de não dito, cuja ironia é mais ousada e inquietante. O tamanho desusado da peça do rei, nos tabuleiros de xadrez usados em Portugal, parece mimar a organização de um reino cujo poder é centralizado na figura do monarca. A palavra re / Re ora é grafada com minúscula, ora com maiúscula, expondo o paralelismo icónico e irónico entre a peça do tabuleiro e o governante do Estado. Além disso, a severidade com que a figura do tabuleiro é usada para agredir o macaco parece desdobrar a que será característica do próprio Rei. A sua presença é muda e estática, como uma sombra imóvel que não precisa de se manifestar para dominar a cena.

26 Ver os comentários de Cristiano Spilla a Amerigo Vespucci, Mundus novus, ed. Cristiano Spilla, testo latino a fronte, Troina, Città Aperta, 2007.

27 Colige detalhada informação sobre as embaixadas portuguesas enviadas ao Papa, nessa época, e sobre as suas repercussões europeias, no campo da arte e das relações entre Estados, Matthias Winner, "Raffael malt einen Elefanten", Mitteilungen des Kunsthistorischen Institutes in Florenz, 11, 1963-1966, pp. 17-109. Ver também, em âmbito específico, Ugo Serani, "La realtà virtuale del Cinquecento: il rinoceronte di Dürer", in "Evós, Tágides minhas". Miscellanea in onore di Luciana Stegagno Picchio, ed. Maria José Lancastre / Silvano Peloso / Ugo Serani, Viareggio, Lucca, Mauro Baroni, 1999, pp. 649-665.

28 O livro teve uma imensa difusão ao longo do século xvi, com oito edições em Itália e várias traduções, mas pouco se sabe acerca do seu autor, que tudo leva a crer fosse um judeu de origem portuguesa exilado em Itália. 
Mas é nas observações finais de Cesare Gonzaga que fica contida a suprema agudeza da pointe. O macaco é tão sapiente que é dottore, o que, cruzado com outras informações epocais que atestam o apego que os portugueses tinham aos títulos, reverte em paródia. O jogo do reverso atinge o seu ápice quando Portugal, país de marinheiros, animais exóticos e viagens até ao novo mundo, tal como fora apresentado no início do capítulo, passa a paese incognito, sendo visto da República dos macacos. É que a grandeza das navegações não parece impressionar a Republica delle simie indiane. Desta feita, a monarquia mais ocidental da Europa, famosa por enviar animais exóticos, em fantásticas embaixadas, a outras nações europeias, faz-se destino de um membro de uma república de macacos indianos. Assim poderá, também ela, ganhar nome e reputação.

Neste episódio, reveem-se, pois, quer particularidades da história do Portugal quinhentista, quer modalidades de relacionamento internacional entre Estados próprias da época. A visão reflete um certo realismo histórico, ao que se acrescenta o "parlar piacevole per indurre riso e festa con gentil modo" que é parte integrante dos códigos de comportamento do perfetto cortegiano ${ }^{29}$. É no espaço de fronteira entre essas duas instâncias que se aloja aquela modelação caricatural e divertida da imagem de Portugal.

5. Portugal reflete-se, nas páginas de Il libro del cortegiano, através de imagens que, apesar do seu discreto número, implicam modalidades de espelhamento diversificadas. A dedicatória a D. Miguel da Silva, com o seu esplendor, oferece-se ao olhar logo no início do livro, como reflexo de conjunto que se projeta num infinito, para depois ir revelando, através do movimento de aproximação resultante da prossecução da leitura, questões essenciais do plano textual, editorial, político-social e diplomático. Por sua vez, o episódio do jogo de xadrez modela uma série de pormenores de escala reduzida, a começar pelo espaço restrito em que a cena se passa, mas os gestos, as palavras e os símbolos que o animam ganham sentido em função de referências antropológicas muito amplas. Superfície côncava e superfície convexa articulam-se e desdobram-se em sucessão, e é também através desse contraponto que, dalle altrui foggie, se passa à regula universallissima.

29 Il libro del cortegiano, p. 182. 